\title{
Numerical and Economical Study of Thermal Insulation in Multi-layer Wall Exposed to Real Climatic Conditions
}

\author{
By Youcef Tamene* \\ Said Abboudi ${ }^{\dagger}$ \\ Cherif Bougriou ${ }^{t}$
}

In this work a numerical study of the thermal behavior of a multilayer building wall ( 3 and 5 layers) is presented. The external side of the wall is subjected to the local atmospheric conditions of Algeria. The finite differences method is used to solve the transient heat transfer equations through the building wall, which is submitted to a solar heat flux, and a convective heat transfer with the environment. A sinusoidal forms of the external temperature and the solar flux were used to approach the measured data of Ouargla city (Algeria) (attitude $31^{\circ} 57^{\prime} \mathrm{N}$, longitude: $5^{\circ} 20^{\prime}$ E, altitude 123-315 m), during the summer and winter seasons. An economic study is presented and a solution for a good thermal insulation at a lower cost is proposed.

\section{Introduction}

Global warming is not currently disputed by the scientific community, according to forecasts; Earth may suffer from a global warming of $1.8 \mathrm{C}$ to 4 $\mathrm{C}$, if no serious measures are taken to reduce greenhouse gas emissions (Kaemmerlen 2009).

One area that consumes a lot of energy and contributes significantly to the proliferation of greenhouse gas emissions is the building sector. A decrease of the energy consummation in buildings, through improved insulation of walls will have consistent economical and environmental benefits.

The building sector is not the only sector concerned with thermal insulation optimization; it appears in all domains where energy consumption is important in volume and cost: for example, the cold rooms (Al-Radaedeh et al 2013), transportation (road, rail, etc.), and in the conservation of foods and medical products. Insulation also has an environmental interest because the reduction of energy consumption remains a priority in the context of sustainable development.

Unfortunately, in Algeria and in many other third world countries, little importance is given to thermal insulation; the price is the most important

${ }^{*}$ Lecturer, University of Batna, Algeria.

${ }^{\dagger}$ Professor, University of Technology of Belfort-Montbeliard, France.

${ }^{\ddagger}$ Professor, University of Batna, Algeria. 
aspect. In the current paper, the research of the optimal configuration for good thermal insulation at a lower cost is presented. For this, we have developed a numerical program in FORTRAN to study the heat transfer in a multi-layer building wall under extreme atmospheric conditions of Ouargla city in the south of Algeria, during the months of January and of July.

\section{Formulation of the Problem}

In this study, we are interested in the external walls of buildings, in order to find the best configuration for good thermal insulation. For this we have studied the case of a wall composed of three layers (Figure 1) and another composed of five layers (Figure 2).

Figure 1. Wall Composed of Three Layers

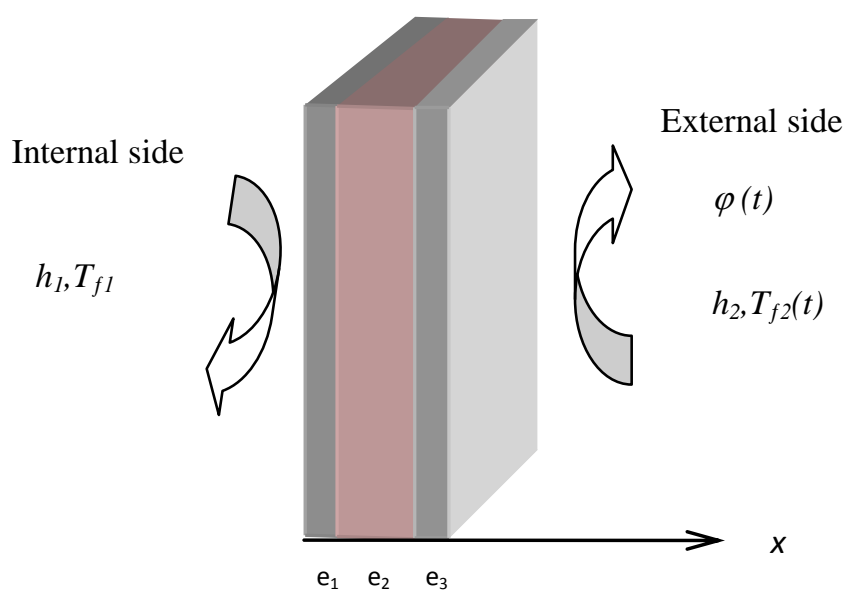

Figure 2. Wall Composed of Five Layers

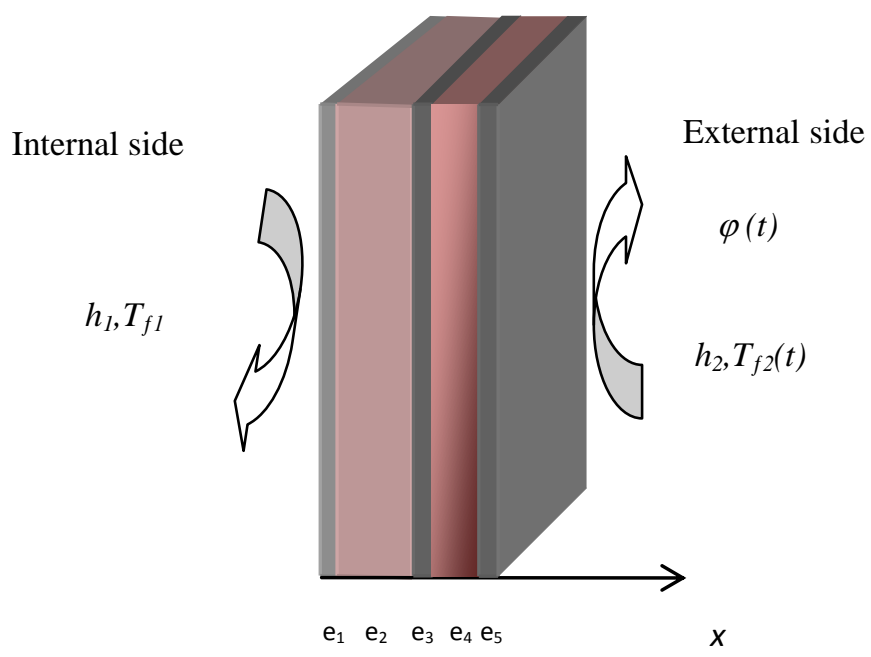


For the solar flux and the external air temperatures, we have chosen to use the climatic data of the region of Ouargla, south of Algeria (attitude $31^{\circ} 57^{\prime} \mathrm{N}$, longitude $5^{\circ} 20^{\prime} \mathrm{E}$, altitude 123 to $315 \mathrm{~m}$ ), during the month of July for its high temperatures and the month of January for its low temperatures.

The measured solar heat fluxes (Capderou 1986), are presented, for the two mentioned months (Table 1).

Table1. Measured Solar Heat Fluxes.

\begin{tabular}{|c|c|c|c|}
\hline \multicolumn{2}{|c|}{ January } & \multicolumn{2}{|c|}{ July } \\
\hline Time (h) & Flux $\varphi\left(\mathrm{w} / \mathbf{m}^{2}\right)$ & Time (h) & Flux $\varphi\left(\mathbf{w} / \mathbf{m}^{2}\right)$ \\
\hline 0 & 0 & 0 & 0 \\
\hline 1 & 160 & 1 & 120 \\
\hline 2 & 320 & 2 & 320 \\
\hline 3 & 450 & 3 & 535 \\
\hline 4 & 550 & 4 & 700 \\
\hline 5 & 570 & 5 & 850 \\
\hline 6 & 550 & 6 & 950 \\
\hline 7 & 450 & 7 & 980 \\
\hline 8 & 320 & 8 & 950 \\
\hline 9 & 160 & 9 & 850 \\
\hline 10 & 0 & 10 & 700 \\
\hline & & 11 & 535 \\
\hline & & 12 & 320 \\
\hline & & 13 & 120 \\
\hline & & 14 & 0 \\
\hline
\end{tabular}

An interpolation of these data leads to the following relationships:

For January month:

$$
\varphi=A^{\prime} \sin \left(\frac{2 \pi t}{\tau}\right) \text { for } 0 \leq t \leq 10 h
$$

$\varphi=0$ for $10 \leq t \leq 24 h$

For July month:

$$
\begin{aligned}
& \varphi=A^{\prime \prime} \sin \left(\frac{2 \pi t}{\tau}\right) \quad \text { for } 0 \leq t \leq 14 h \\
& \varphi=0 \text { for } 14 \leq t \leq 24 h
\end{aligned}
$$

Were $A^{\prime}=570$ and $A^{w}=980$

Figures 3 and 4, show a good agreement between the proposed relationships and the measured heat flux. 
Figure 3. Solar Heat Flux for July

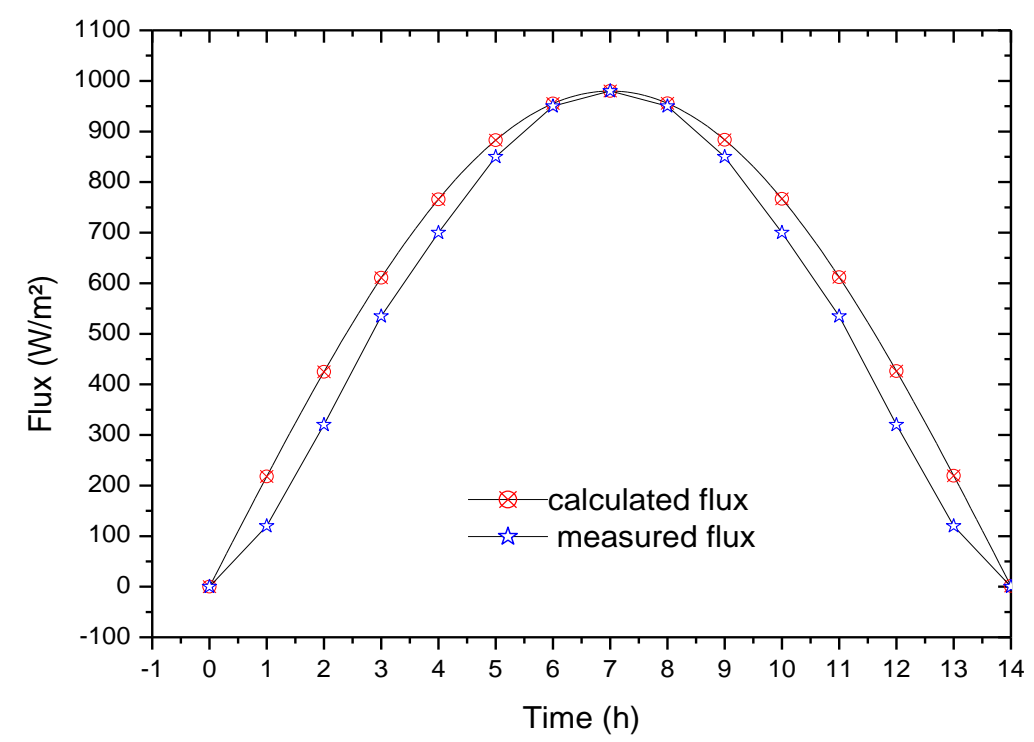

Figure 4. Solar Hear Flux for January

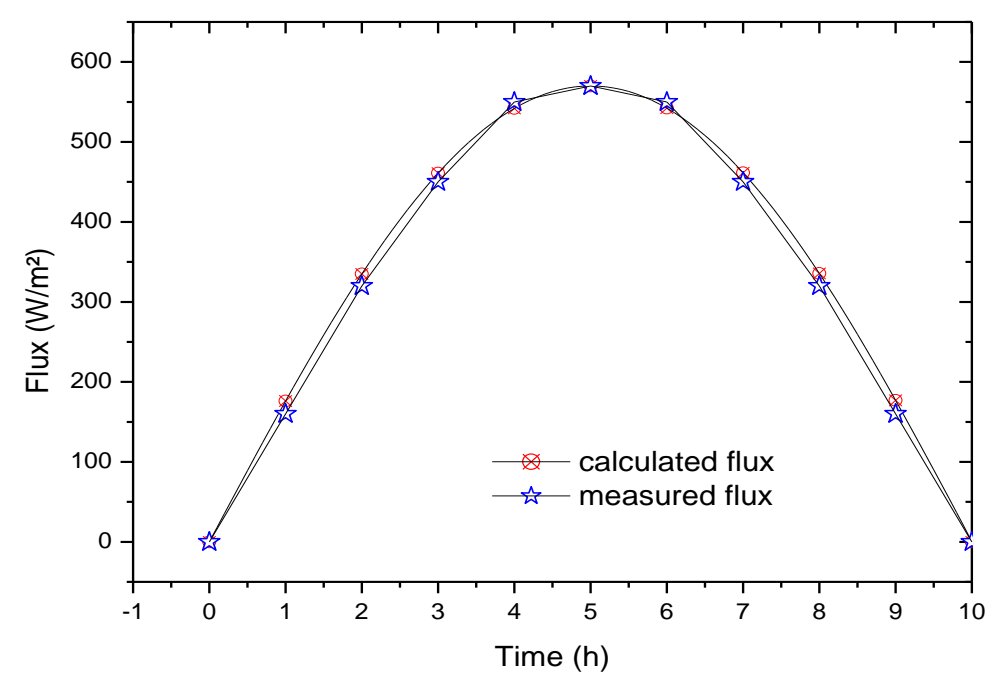

The values of the average maximum temperature and average minimum temperature are used to find the relationship below.

$T=A \sin \left(\frac{2 \pi t}{\tau}\right)+B$ for $0 \leq t \leq 24$

Were $A=7,05$ and $B=10,95$ for January

And $A=8,1$ and $B=36,8$ for July

We represent this relation in Figures 5 and 6 . This corresponds to the measured values, obtained from the international website of meteorology, http://www.tutiempo.net/en/Climate/Ouargla/, (Table 2). 
Figure 5. Evolution of the Temperature for July

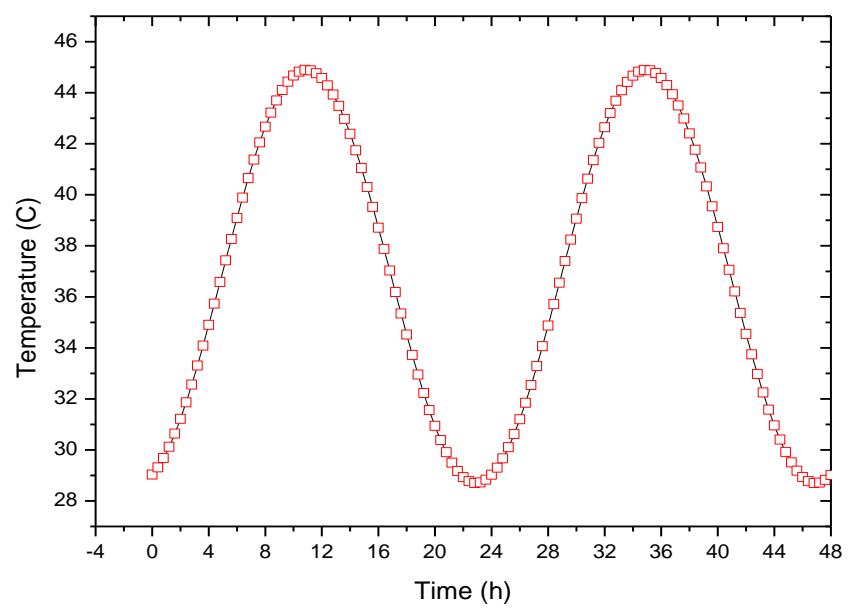

Figure 6. Evolution of the Temperature for January

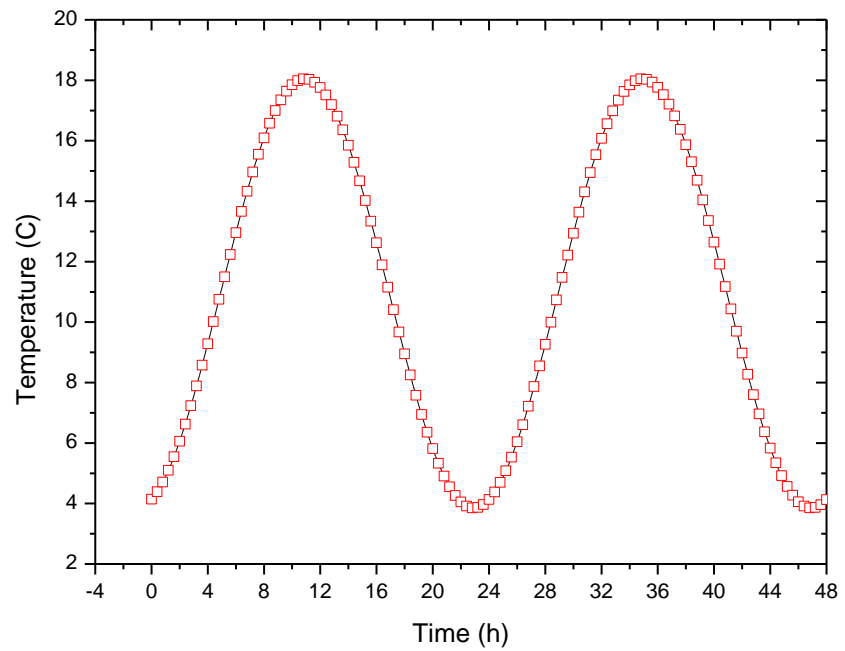

Table 2. Measured Temperatures

\begin{tabular}{|c|c|c|c|c|c|c|c|c|c|}
\cline { 2 - 11 } \multicolumn{1}{c|}{} & \multicolumn{2}{|c|}{ January } & \multicolumn{2}{c|}{ July } & & \multicolumn{2}{c|}{ January } & \multicolumn{2}{c|}{ July } \\
\hline Day & $\mathbf{T}_{\mathbf{M}}$ & $\mathbf{T}_{\mathbf{m}}$ & $\mathbf{T}_{\mathbf{M}}$ & $\mathbf{T}_{\mathbf{m}}$ & Day & $\mathbf{T}_{\mathbf{M}}$ & $\mathbf{T}_{\mathbf{m}}$ & $\mathbf{T}_{\mathbf{M}}$ & $\mathbf{T}_{\mathbf{m}}$ \\
\hline 1 & 19 & 2,5 & 45,8 & 29 & 17 & 16,4 & 2 & 41 & 29,5 \\
\hline 2 & 20,4 & 2 & 43,6 & 28,4 & 18 & 13,5 & 9 & 40,4 & 28,7 \\
\hline 3 & 20,1 & 6,4 & 44 & 30 & 19 & 15,5 & 7 & 38,9 & 25,8 \\
\hline 4 & 17,5 & 6 & 46 & 28,4 & 20 & 16 & 4,5 & 40,6 & 24,4 \\
\hline 5 & 19,6 & 1 & 47 & 31,8 & 21 & 16,6 & 4 & 44 & 26 \\
\hline 6 & 24 & 6 & 48,3 & 31,2 & 22 & 13,4 & 7,4 & 43,8 & 26 \\
\hline 7 & 17,8 & 5 & 48,6 & 32 & 23 & 16,7 & 7,5 & 37,5 & 26,2 \\
\hline 8 & 18,2 & 1,6 & 48,3 & 32,5 & 24 & 20 & 4,7 & 37,7 & 24,5 \\
\hline 9 & 18 & 1 & 48,3 & 33 & 25 & 21,1 & 4 & 41,6 & 25 \\
\hline
\end{tabular}




\begin{tabular}{|c|c|c|c|c|c|c|c|c|c|}
\hline 10 & 17,4 & 1 & 48 & 31,1 & 26 & 19,3 & 4,3 & 45,5 & 24,4 \\
\hline 11 & 16,5 & 0 & 46,5 & 30 & 27 & 20 & 4,3 & 45 & 29 \\
\hline 12 & 16,2 & 0,1 & 47 & 29,2 & 28 & 16,8 & 7 & 46 & 25 \\
\hline 13 & 16,5 & 0 & 48 & 29,9 & 29 & 20 & 6,2 & 46 & 28,5 \\
\hline 14 & 19,5 & 0,4 & 49 & 30,1 & 30 & 15,3 & 6,5 & 46,8 & 29,4 \\
\hline 15 & 20,5 & 0,6 & 49,6 & 31 & 31 & 17,8 & 6,5 & 45 & 30 \\
\hline 16 & 20 & 2 & 43,5 & 31,2 & & & & & \\
\hline
\end{tabular}

$\mathrm{T}_{\mathrm{M}}$ : Maximal temperature $\left({ }^{\circ} \mathrm{C}\right)$

$\mathrm{T}_{\mathrm{m}}$ : Minimal temperature $\left({ }^{\circ} \mathrm{C}\right)$

\section{Numerical Resolution}

\section{Assumptions}

Heat transfer in the wall is one dimensional and unsteady.

- Physical properties are constants.

- There are no heat sources in the wall.

So, the heat transfer in the multilayer wall is governed by the following equations:

$$
\alpha_{i} \frac{\partial^{2} T_{i}}{\partial x^{2}}=\frac{\partial T_{i}}{\partial t}, l_{i-1} \leq x \leq l_{i}, t>0, i=1, \ldots, 5
$$

Where:

$\alpha_{i}=\frac{\lambda_{i}}{\rho_{i} C_{i}}, l_{0}=0, l_{i}=l_{i-1}+e_{i}, L=l_{5}$

And the boundary and initial conditions

Boundary conditions

$$
\begin{aligned}
& -\lambda_{1} \frac{\partial T_{1}}{\partial x}=h_{1}\left(T_{f 1}-T_{1}\right) \quad x=0 \\
& \lambda_{i} \frac{\partial \boldsymbol{T}_{i}}{\partial x}=\lambda_{i+1} \frac{\partial \boldsymbol{T}_{i+1}}{\partial x}, \quad \boldsymbol{T}_{i}=\boldsymbol{T}_{i+1} \quad x=l_{i}, i=1,4 \\
& -\lambda_{3} \frac{\partial T_{3}}{\partial x}=h_{2}\left(T_{3}-T_{f 2}\right)-\beta \varphi(t) \quad x=l_{5}
\end{aligned}
$$

where $\beta=0.3$

Initial conditions:

$T_{i}=T_{0} \quad$ for $t=0$ and $\quad 0 \leq x \leq l_{5}$

The resolution of the system of equations (6) with boundary conditions (7), (8), (9) and initial conditions (10) is performed by the finite differences method according to the Cranck-Nicolson scheme (Gerald 1978). In every instance, the 
Tri Diagonal Matrix Algorithm (TDMA) (Boumahrat and Gourdi.1993) is used to solve the obtained algebraic system.

The simulated results are performed for common materials used in building constructions. Their physical properties (the specific heat $\mathrm{C}_{\mathrm{p}}$, the mass density $\rho$ and the thermal conductivity $\lambda$ ) are presented in Table 3, (Tamene et al 2011), (Bekkouche et al 2003).

Table 3. Physical Characteristics

\begin{tabular}{|c|c|c|c|c|c|}
\hline & Brick & Mortar & Plaster & Air & Polystyrene \\
\hline$\rho\left(\mathrm{kg} / \mathrm{m}^{3}\right)$ & 1900 & 2050 & 825 & 1.2 & 29 \\
\hline $\mathrm{C}_{\mathrm{p}}(\mathrm{j} / \mathrm{kg} \cdot \mathrm{k})$ & 920 & 950 & 1000 & 1008 & 1850 \\
\hline$\lambda(\mathrm{w} / \mathrm{km})$ & 1.11 & 1.96 & 0.25 & 0.026 & 0.04 \\
\hline
\end{tabular}

The initial and boundary conditions used are:

$h_{1}=5 \mathrm{~W} / \mathrm{m}^{2 \circ} \mathrm{C}, h_{2}=10 \mathrm{~W} / \mathrm{m}^{2}{ }^{\circ} \mathrm{C}, T_{f 1}=25^{\circ} \mathrm{C}, T_{0}=T_{m}$

\section{Results and Discussion}

To verify the program, we have compared the results obtained by calculating the temperatures at the interfaces in the steady state with those calculated by the program in the case of a wall composed with five layers (configuration 2). The solar flux is made zero, and the indoor and outdoor air temperature are taken as constants.

Numerically, the number of steps used in each layer is as follows:

$$
N_{1}=8, \quad N_{2}=30, N_{3}=12, \quad N_{4}=15 \text { and } N_{5}=8
$$

At steady state, and based on the relationship of the flux we have:

$\phi=\frac{T_{f 1}-T_{f 2}}{R} \quad$ with $T_{f 1}=25^{\circ} \mathrm{C}$ and $T_{f 2}=45^{\circ} \mathrm{C}$

$R=R_{1}+R_{2}+R_{3}+R_{4}+R_{5}+R_{6}+R_{7}=\frac{1}{h_{1}}+\frac{e_{1}}{\lambda_{1}}+\frac{e_{2}}{\lambda_{2}}+\frac{e_{3}}{\lambda_{3}}+\frac{e_{4}}{\lambda_{4}}+\frac{e_{5}}{\lambda_{5}}+\frac{1}{h_{2}}$

$T_{\mathrm{i}+1}=T_{\mathrm{i}}-\phi R_{i+1} \quad$ were $i=0,6 \quad T_{0}=T_{f 1} T_{7}=T_{f 2}$

The interface temperatures obtained at steady state are the same as predicted analytically, Figure 7. 
Figure 7. Evolution of the Temperature through the Multilayer Wall

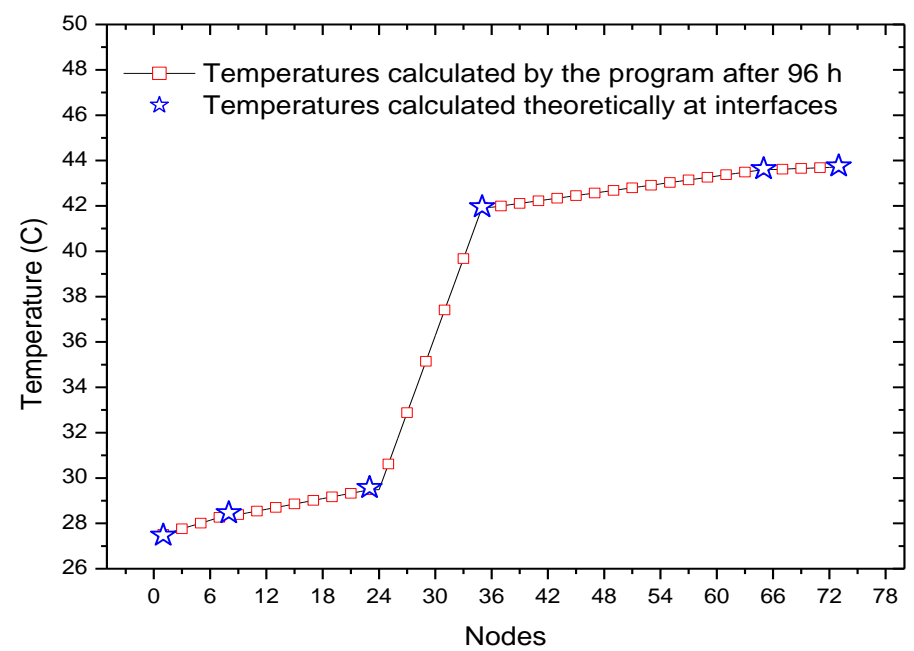

Several configurations of multi-layer materials (Table 4) were analyzed to find the best material providing better thermal insulation with a lower cost.

Table 4. Different Configurations

\begin{tabular}{|c|c|c|c|c|}
\hline Thickness & Configuration 1 & Configuration 2 & Configuration3 & Configuration 4 \\
\hline$e_{1}$ & $2 \mathrm{~cm}$ plaster & $2 \mathrm{~cm}$ plaster & $2 \mathrm{~cm}$ plaster & $2 \mathrm{~cm}$ plaster \\
\hline$e_{2}$ & $10 \mathrm{~cm}$ brick & $10 \mathrm{~cm}$ brick & $30 \mathrm{~cm}$ brick & $15 \mathrm{~cm}$ brick \\
\hline$e_{3}$ & $4 \mathrm{~cm}$ air & $4 \mathrm{~cm}$ polys & $2 \mathrm{~cm}$ mortar & $2 \mathrm{~cm}$ mortar \\
\hline$e_{4}$ & $15 \mathrm{~cm}$ brick & $15 \mathrm{~cm}$ brick & 0 & 0 \\
\hline$e_{5}$ & $2 \mathrm{~cm}$ mortar & $2 \mathrm{~cm}$ mortar & 0 & 0 \\
\hline
\end{tabular}

For all cases, the internal temperatures calculated for the month of July month are presented in Figures 8 and 9. For each configuration, the domain variation of the temperature is:

Configuration $1: 26.75^{\circ} \mathrm{C} \leq \mathrm{T} \leq 27.15^{\circ} \mathrm{C}$

Configuration 2: $27.45^{\circ} \mathrm{C} \leq \mathrm{T} \leq 28.05^{\circ} \mathrm{C}$

Configuration $3: 30.75^{\circ} \mathrm{C} \leq \mathrm{T} \leq 33^{\circ} \mathrm{C}$

Configuration $4: 27.5^{\circ} \mathrm{C} \leq \mathrm{T} \leq 35^{\circ} \mathrm{C}$ 
Figure 8.The Temperature of the Internal Side $\left(1^{\text {st }}\right.$ and $2^{\text {nd }}$ Configuration $)$

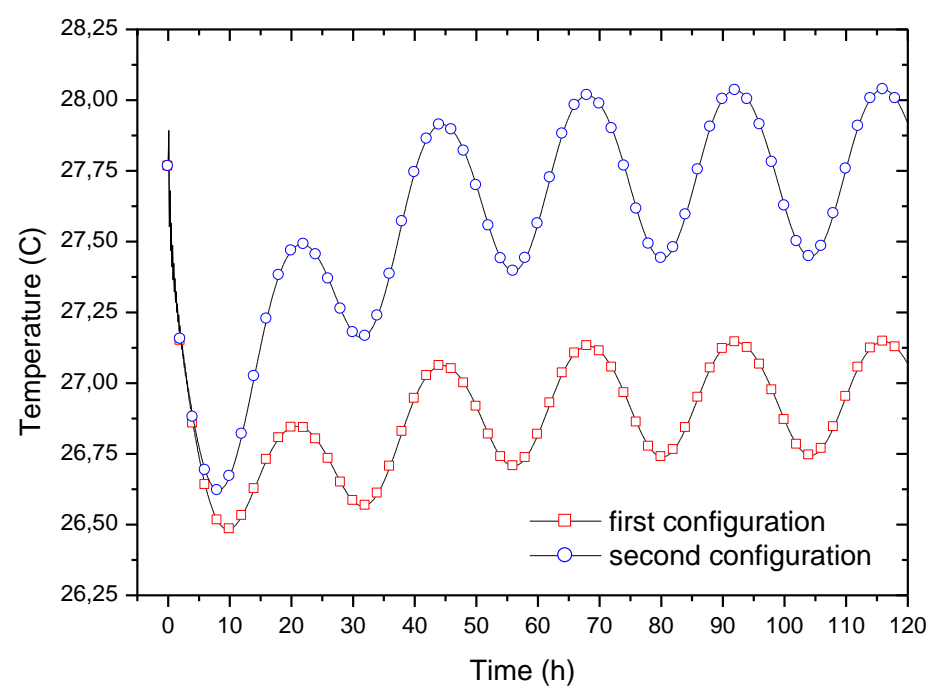

Figure 9.The Temperature of the Internal Side ( $3^{\text {rd }}$ and $4^{\text {th }}$ Configuration)

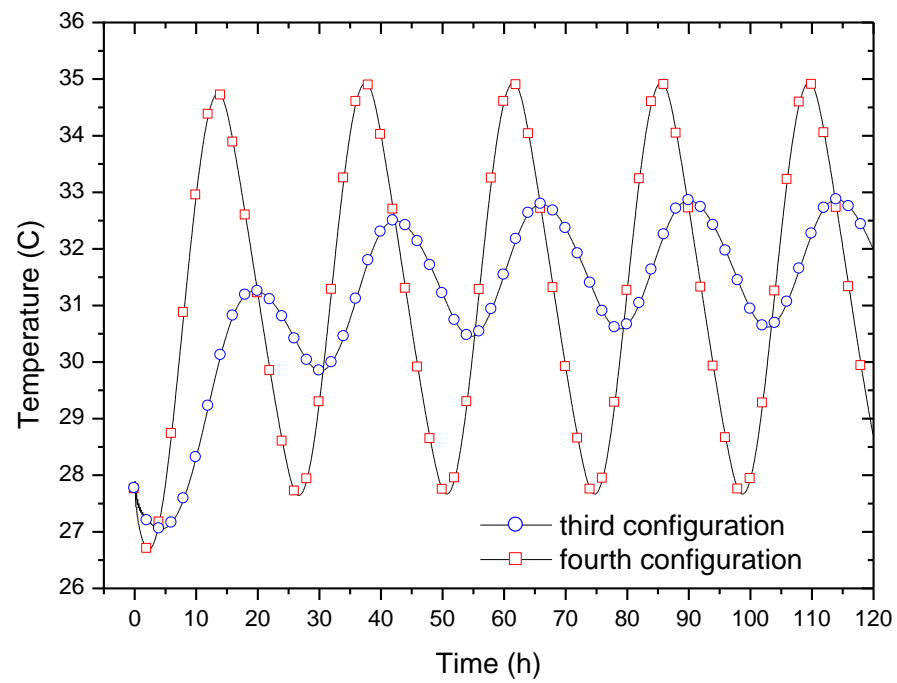

Since, in summer the internal temperature must be as low as possible relative to the external temperature, we note that for good thermal insulation, in summer the first configuration is better than the second, the third and the fourth.

Similarly, the results of January are presented in Figures 10 and 11

However, we see that the temperature change is as follows:

Configuration $1: 23.75^{\circ} \mathrm{C} \leq \mathrm{T} \leq 24.5^{\circ} \mathrm{C}$

Configuration 2: $23.5^{\circ} \mathrm{C} \leq \mathrm{T} \leq 24^{\circ} \mathrm{C}$

Configuration $3: 21.5^{\circ} \mathrm{C} \leq \mathrm{T} \leq 22.75^{\circ} \mathrm{C}$

Configuration $4: 19^{\circ} \mathrm{C} \leq \mathrm{T} \leq 22.75^{\circ} \mathrm{C}$ 
Figure 10.The Temperature of the Internal Side ( $1^{\text {st }}$ and $2^{\text {nd }}$ Configuration)

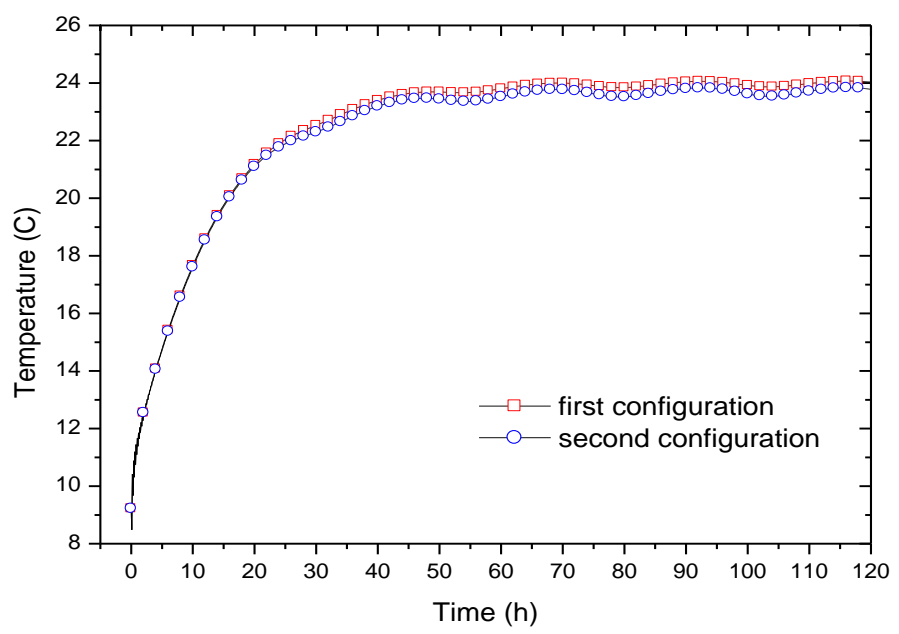

Figure 11.The Temperature of the Internal ( $3^{\text {rd }}$ and $4^{\text {th }}$ Configuration)

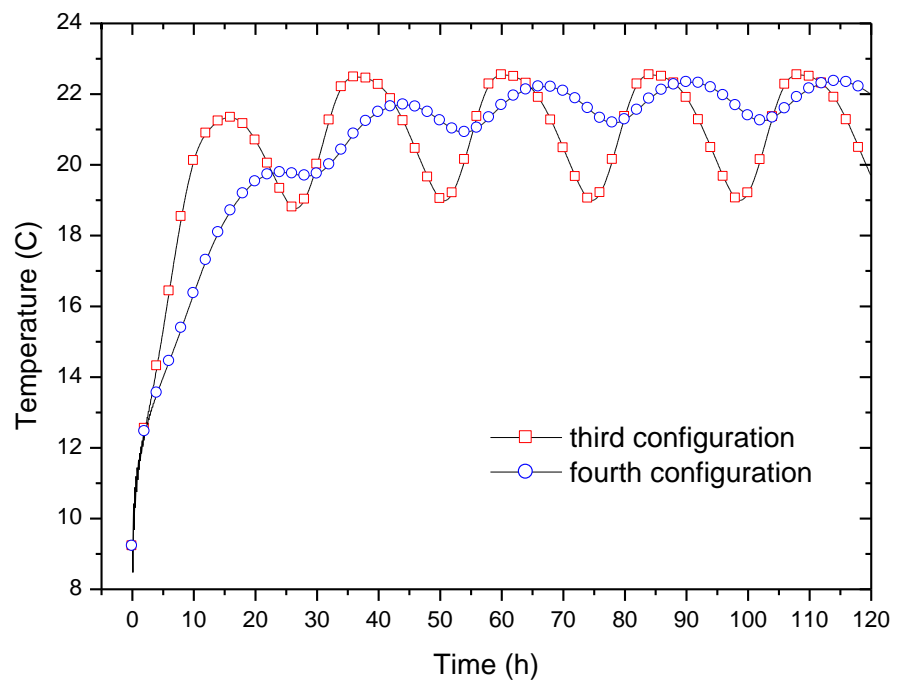

In winter, the internal temperature must be as high as possible relative to the external temperature; we note that for good thermal insulation, in winter the first configuration is better than the second, the third and the fourth.

\section{Economical Study}

From the thermal analysis presented above, we propose an economic analysis in terms of cost for the four configurations. The materials used are 
brick and polystyrene. Their prices are shown in Table 5; for the internal and external layers it is the same for the four configurations.

Table 5. Material Prices (120 DA = 1 Euro).

\begin{tabular}{|c|c|c|}
\hline Materials & Dimensions $(\mathrm{cm})$ & Price (DA) \\
\hline Brick 12 & $30 \times 20 \times 15$ & 30 \\
\hline Brick 8 & $30 \times 20 \times 10$ & 20 \\
\hline Polystyrene & $200 \times 100 \times 4$ & 300 \\
\hline
\end{tabular}

The number of bricks required, for a surface wall ( $4 \mathrm{~m} \times 3 \mathrm{~m})$, is:

$\mathrm{M}_{1}=\frac{12}{0.3 \times 0.2}=200$

Then the cost is: $P_{1}=30 M_{1}=6000 \mathrm{DA}$

And the cost of a double wall of brick is: $P_{2}=2 P_{1}=12000 \mathrm{DA}$

For a wall thickness of $10 \mathrm{~cm}$, the number of bricks required is:

$\mathrm{M}^{r}{ }_{3}=\frac{12}{0.3 \times 0.2}=200$

Then the cost is: $\mathrm{P}_{3}{ }_{3}=20 \mathrm{M}_{3}^{r}=4000 \mathrm{DA}$

The number of the polystyrene plate required is: $\mathrm{M}_{4}^{w}=\frac{12}{1 \times 2}=6$

And the price of polystyrene is: $\mathrm{P}_{4}=300 \mathrm{M}^{w}{ }_{4}=1800 \mathrm{DA}$

So, the cost of a double wall of $15 \mathrm{~cm}$ and $10 \mathrm{~cm}$ of brick spaced with a $4 \mathrm{~cm}$ layer of polystyrene is: $\mathrm{P}^{\prime \prime}{ }_{5}=\mathrm{P}^{\prime \prime}{ }_{1}+\mathrm{P}^{t}{ }_{3}+\mathrm{P}_{4}=11800 \mathrm{DA}$

And the cost of a double wall of $15 \mathrm{~cm}$ and $10 \mathrm{~cm}$ of brick spaced a $4 \mathrm{~cm}$ layer of air is: $\mathrm{P}_{6}^{\prime \prime}=\mathrm{P}_{1}^{\prime}+\mathrm{P}_{3}=6000+4000=10000 \mathrm{D}$.A

A summary of the prices of the four configurations in Euro is shown in Table 6.

Table 6. Configurations Prices

\begin{tabular}{|c|c|c|c|c|}
\hline Configuration & First & second & third & fourth \\
\hline Price (Euro) & 83.33 & 98.33 & 100 & 50 \\
\hline${\text { Price per } \mathrm{m}^{2} \text { (Euro) }}^{2}$ & 6.94 & 8.19 & 8.33 & 4.16 \\
\hline
\end{tabular}

From a viewpoint of heat insulation and price, the first configuration is better than the second and third. Note that the fourth configuration is the cheaper, but it ensures poor thermal insulation.

\section{Conclusion}

A numerical study of the thermal behavior of a multi-layer wall for four configurations used in buildings, is presented. The real climatic conditions (the measured solar flux and the temperature of external air) of Ouargla city are used to find the better thermal insulation in winter and summer, at a lower cost. An economic study has been presented and it is shown that it is possible to have good thermal insulation at a lower price. To have a good thermal 
insulation at a cheaper cost, we recommend the first configuration. The study is also based on long-term energy consumption environment protection.

\section{References}

Al-Radaedeh, J., Al-Zgoul, B., Frehat, M. 2013. Selection of Thermal Insulation Thickness of Cold Store Enclosures.Innovative Systems Design and Engineering.4 (14).

Bekkouche, S.M.E., Benouaz, T., Cheknane, A. 2003. A Modelling approach of thermal insulation applied to a Saharan building.Thermal Science. 35. 631-644.

Boumahrat, M., Gourdi, A. 1993. Méthodes Numériques Appliqués. Office des Publications Universitaires, Algérie.

Capderou, M. 1986. Atlas solaire de l'Algérie, Tome 2. Office des Publications Universitaires, Algérie.

Gerald, C.F. 1978. Applied Numerical Analysis. Addison Wesley publishing Company.

Kaemmerlen, A. 2009. Transfert de chaleur à travers les isolants thermiques du bâtiment. Thèse de doctorat, Université Henri-Poincaré, Nancy.

Tamene, T., Abboudi, S., Bougriou, C. 2011. Study of heat and moisture diffusion through a wall exposed to solar heat flux.Journal of Engineering Science and Technology. Vol. 6, No. 4. 429 - 444.

Websites

http://www.tutiempo.net/en/Climate/Ouargla/ 